\title{
Study on Adverse Selection and Moral Hazard in the Construction of Rural Circulation System*
}

\author{
Jingfei Ran \\ Sias International University \\ Zhengzhou, China 450002
}

\begin{abstract}
Circulation is the blood of economic and social development, but the irregular circulation order in China's rural areas has been disturbing the rural economic development. There are widespread difficulties in circulation enterprises management, and adverse selection prevails. In terms of the adverse selection of rural circulation enterprises, the Chinese government should increase the input of information cost and establish a credit database of circulation enterprises; establish the complaint acceptance mechanism of rural consumers; develop e-commerce and improve the development level of rural logistics; improve the after-sale service system of rural commodities; and improve the degree of scale operation of circulation enterprises.
\end{abstract}

Keywords—non-public economy; adverse selection; rural circulation system

\section{INTRODUCTION}

Circulation is the blood of economic and social development, maintaining the normal operation of economic society. And circulation industry is related to the circulation of the whole society, and plays an important role in promoting production, guiding consumption, and promoting economic restructuring. In recent years, although China's rural economy has developed rapidly, the actual situation of rural circulation system construction is still not optimistic, and the commodity circulation between cities and villages is not smooth. In order to build a rural circulation system, the state has promulgated a series of principles and policies, such as Home Appliance Going Rural, Five "One" Project and New Network Project, which has improved the circulation environment in rural areas and perfected the circulation system in rural areas to a great extent. However, from the actual results, the Henan farmers' difficulty of selling has not been fundamentally solved. In recent years, events such as "Radish Brother" and "Yam Brother" have aroused great sensation in the media in Henan. It shows that the construction of rural circulation system is still very arduous and heavy.

The circulation order in rural areas is not standard enough. Fake selling and counterfeiting are still common in rural

*This paper is a partial result of Henan Province social science fund's Study on Mode and Realization Path of Ecological Transformation of Water Source Industry in the Middle Route of South-to-North Water Diversion Project and Henan Provincial Department of Science and Technology's Study on Impact of Agricultural Productive Service Industry on Henan's Agricultural Economy

CLC No.: F324 circulation market, which is more serious in rural areas because of the low level of consumption and supervision in rural areas. Under the restriction of circulation management system, all kinds of supervision in cities are relatively powerful. With the city's large supermarkets and stores paying thinking highly of brand building, most businesses can restrain their own behavior, so the order of commodity circulation in the city is relatively orderly. In order to avoid risks and exploit excessive profits, some vendors and enterprises with poor legal awareness put inferior goods mainly in the rural market with relatively loose supervision. They sell not only all kinds of counterfeit and inferior consumer goods, such as soap, food and beverages, but also fake agricultural products, such as fake pesticides and fake seeds, which will harm farmers and destroy agricultural production, and cause irreparable losses to farmers and agriculture.

Therefore, in the process of investing in rural circulation, due to the imperfect credit system of different enterprises, the information of circulation enterprises operating regular commodities and the ones operating fake commodities cannot be public. Driven by opportunism and maximization of utility, the information about quality is concealed. So that the investment of formal commodities and other aspects are facing greater risks, eventually the enterprises with poor quality expel the ones with good quality, resulting in adverse selection.

At present, at home and abroad there are many researches on circulation enterprises investing in rural circulation system. Christopher Gan (2011) believes that the relatively inadequate Internet and telephone users in rural areas cause the blocked information of agricultural products sales. The convenience of rural residents will affect the consumption credit. Most market players rely on wholesale markets for information on supply and marketing, or rely on collecting information from farmers, marketing terminals, and other business partners. Many enterprises engaging the import and export trade of agricultural products have not mastered the skills and methods of collecting business information online and making contracts. Therefore, it is very important for circulation enterprises to participate in the construction of rural circulation system. Shiyuan Wuzheng (2004) and Yin Hanning (2007) consider that the best method to build a rural circulation network system is integrating the existing circulating resources in urban and rural areas and realizing the integration of urban and rural commerce. That is, a relatively developed city in business and trade stands at the height of the integration of urban and rural commerce to formulate various development strategies, such 
as format selection, layout optimization, infrastructure construction, logistics and distribution, e-commerce and so on. And it necessary to promote the commercial forms, circulation means and consumption modes of circulating enterprises in cities to rural market step by step, so that the modern circulation system should be established through the transformation of mass production - a large number of sales systems. Tian Zhenyu (2002) believes that adverse selection is the main problem in the operation of rural circulation enterprises, and the supervision of enterprises by government regulation can reduce the adverse selection of enterprises. Chen Hui and Shan Guoli (2006) analyzed the formation process of adverse selection of rural circulation enterprises by mathematical model. It is theoretically proved that the asymmetric distribution of information between circulation enterprises operating regular commodities and the ones operating fake commodities is an important reason why circulation enterprises are unwilling to go to the rural area. Zheng Hui (2007) proposed a signal transmission model and an information screening model to solve the adverse selection caused by the asymmetric information between circulation enterprises operating regular commodities and the ones operating fake commodities.

At present, most of the existing literatures discuss the influence of macroeconomic system and objective environmental factors on the investment of circulation enterprises in rural circulation system, and analyzes from an empirical view. But from the quantitative point of view, there are deficiencies and lack of practical solutions to the proposal. Based on the theory of information economics and game theory, first the paper defines the adverse selection and moral hazard faced by circulation enterprises in investing in rural circulation. And this paper establishes a game model formed by the adverse selection in enterprises, and puts forward that signal transmission is an effective method to solve the problem of adverse selection. Finally, based on these, the paper puts forward practical solutions to solve the adverse selection of circulation in circulation enterprises investing in rural area.

\section{ADVERSE SELECTION AND MORAL HAZARD OF CIRCULATION ENTERPRISES AND RURAL CONSUMERS}

\section{A. Problem of Adverse Selection of Rural Consumers}

Professor George George A. Akerlof, an American economist, put forward that in a market transaction, if one party of can benefit from more information than the other party and the other party is damaged, the party with information inferiority is difficult to make a successful decision. As a result, the price will be distorted and the market efficiency will be reduced. The quality products will be driven out of the market by inferior quality products. In rural circulation, adverse selection refers to the operators in the market who are most likely to produce disadvantage (adverse) results (i.e. to operate counterfeit and inferior products). They are often those who are most active in rural management and most likely to be profitable.

In order to analyze the formation of adverse selection in rural circulation, the paper considers that in a competitive rural circulation system, the operating income of rural circulation is an increasing function of interest rate. Assuming that there are two investment projects, the circulation enterprise that operates regular commodities and another one that operates counterfeit and inferior commodities, the two enterprises have two results: success or failure. All enterprises have the same mean income $\mathrm{T}$ for farmers, and farmers know $\mathrm{T}$, and the probability of success of $A$ project is $B$, the income of farmers is $y$; the probability of success of $B$ project is $£$ and the farmer's income is $\mathrm{R}$. If the two projects fail, the farmer's income is 0 . Assuming that the operating profit of each project is 1 and the farmer is the only demander, the average profit margin of capital is $r$. If the project is successful, the farmer will get P US dollars; if it fails, it will be 0 ; therefore, the expected profit of the enterprise is:

$$
¥=\mathrm{p} \mathrm{r}((\mathrm{y}+£ \mathrm{R}) /(\mathrm{y}+\mathrm{R})
$$

Take $\mathrm{G}$ as the expected income of farmers, there is: $\mathrm{G}=$ $ß y+£ R$

Therefore, farmers tend to choose the circulation enterprises that operate regular commodities. However, due to the asymmetrical information, farmers are unable to distinguish the quality of enterprises' credit and engineering. Therefore, farmers will adopt a way to reduce costs and increase their expected returns. Because farmers can not accurately distinguish the status of circulation enterprises, they will choose to reduce prices to increase the expected earnings. Lowering the price will make the circulation enterprises which operate regular commodities withdraw from the market, thus increasing the average risk of farmers' consumption. But it may reduce the expected income of farmers. Ultimately, only the circulation enterprises that operate inferior products can continue to operate, and the enterprises that operate regular circulation products will withdraw from the market. The market will be occupied by the circulation enterprises operating inferior quality products, that is, the high-risk and high-yield companies. While the low-risk and low-yield companies will gradually withdraw from the market. As a result, the circulation enterprises that operate inferior commodities expel the enterprises that operate regular commodities, so the adverse selection in the construction of rural circulation system appears.

\section{B. Moral Hazard Problem of Circulation Enterprises}

With the development of rural circulation system, more and more circulation enterprises will participate in rural circulation. According to the analysis above, we can define the circulation enterprise that manages regular commodities as a good enterprise, while the one that manages inferior commodities as a poor enterprise. The worse the enterprise is, the higher its risk is. So that the harm to the construction of rural circulation system will be greater and the probability of consumer losses to farmers will be higher. Farmers need to consider various factors in choosing the circulation entity, and the demand for consumer surplus is higher. Generally speaking, the expected income of farmers depends on the quality and price of products of rural circulation entity, and the price of products depends on the quality. Driven by opportunism and maximization of utility, the circulation enterprises operating poor quality products may have moral hazards arising from the 
eagerness to profit by hiding information about quality and credit.

From the view of game theory, the payment matrix of game of circulation enterprises and rural consumers is as follows in the game model of consumers and rural circulation enterprises under complete information.

TABLE I. GAME MODEl OF CONSUMERS AND RURAL CIRCULATION ENTERPRISES

\begin{tabular}{|lc|c|c|}
\hline & \multicolumn{1}{|c|}{ Nonoccurrence of Opportunistic Behavior } & Occurrence of Opportunistic Behavior \\
\hline $\begin{array}{l}\text { Offering } \\
\text { service }\end{array}$ & high-quality & $\left(F+\alpha a_{g}-c_{\varepsilon}\right),\left(r_{g}-\alpha r_{g}-F-c_{k}\right)$ & $\left(F+\alpha a_{z}-c_{b}+t c_{0}\right),\left(\beta r_{g}-\alpha r_{g}-F-c_{h}-t c_{0}\right)$ \\
\hline $\begin{array}{l}\text { Offering } \\
\text { service }\end{array}$ & poor-quality & $\left(F+\alpha a_{b}-c_{b}\right),\left(r_{b}-\alpha r_{b}-F-c_{k}\right)$ & $\left(F+\alpha a_{b}-c_{b}+t c_{0}\right),\left(\beta r_{b}-\alpha r_{b}-F-c_{k}-t c_{0}\right)$ \\
\hline
\end{tabular}

In a game, due to $r_{g}-r_{b}<c_{g}-c_{b}$, the profit of the circulation enterprise providing inferior service is higher than that providing superior service, the circulation enterprise's dominant strategy is to provide inferior goods. Whether there is the opportunism behavior of rural consumers depends on the situation: (1) When $(\boldsymbol{B}-\mathbf{1}) r_{g}>\boldsymbol{c}_{0}$, no matter whether the circulation enterprises provide quality commodities, the profit under rural consumers' choice of opportunistic behavior is significantly higher than that without opportunistic behavior. Therefore, the dominant strategy of rural consumers is an opportunistic behavior. Therefore, for rational participants in a static game, the provision of inferior goods, the occurrence of opportunistic behavior is dominant-strategy equilibrium. The realistic explanation for this nash equilibrium is: Distribution enterprises only provide inferior products for the immediate interests while ignoring the rights and interests of rural consumers, and the long-term development of enterprises. Some circulation enterprises even take the purpose of collecting money, and regard the service for the rural consumers as a hammer deal. Especially, some rural circulation enterprises make use of the regular market in rural areas, material exchange meetings to vigorously promote inferior products. At the same time, due to the lack of supervision, some low-quality vendors can take advantage of opportunistic behavior to damage the interests of circulation enterprises and ultimately achieve their own short-term benefits. (2) When $(\beta-1) r_{o}<t c_{o}$, because the probability or cost of opportunistic behavior to be detectedis is larger, and exceeds the benefits it can bring, the risk-neutral consumers will not choose opportunistic behavior, so (providing poor quality goods without opportunistic behavior) is the dominant strategic equilibrium of the game. But this is not a stable equilibrium, and the provision of inferior commodities will not only aggravate the contradictions between circulation enterprises and rural consumers, but also affect the brand image of circulation enterprises, resulting in the decline of circulation efficiency and ultimately lead to the exiting of rural consumers.

In the process of the construction of China's rural circulation system, the operation difficulties of circulation enterprises are widespread. With the prevalent adverse selection, and the lack of a good business environment is highlighted. The influence of information asymmetry on circulation enterprises investing in rural circulation construction can be analyzed from the following aspects: First, there are obstacles in the information transmission between rural areas. Because of the remote geographical location and lack of information sources for farmers, it will affect the transmission of an enterprise's real business information. One of the main differences between rural and urban areas is that many villages are tens of kilometers apart because of the relatively scattered living conditions in rural areas. Despite the great progress made in the village-to-village project, the inconvenience of transportation is still the biggest obstacle faced by rural residents. All these have led to the rural information transmission is not smooth, and there is no effective communication mechanism between rural consumers; in addition, the general cultural level of rural residents is not high, and most of them is below junior college, so rural consumers are generally lack of the ability to identify goods, who cannot effectively distinguish for real and false goods. Second, the unbalanced development and application of information technology such as digital technology and network technology deepen the asymmetric distribution of information. Despite the recent signing of rural e-commerce cooperation agreements by elite e-commerce enterprises such as Alibaba and rural areas in several provinces in China, with the Chinese rural market as a whole, the countryside is still in the early stage of information society. And due to the problem of quality there are fewer Internet users among many farmers. So it is far from the transmission of urban circulation information. The backwardness of information technology makes it impossible for rural consumers to distinguish fake and inferior commodities by some advanced means such as electronic commerce. Therefore, the underdevelopment of rural information technology is one of the important reasons for its asymmetric information. Third, the backwardness of rural logistics level makes it difficult for information transmission to reach consumers' terminal effectively. The development of rural logistics has been facing an important problem, that is, many commodities cannot directly reach the hands of rural consumers. This has weakened the willingness of many rural consumers to buy goods online. And over time, rural residents' interest in online shopping and e-commerce is decreased, and another channel of information transmission is blocked. Fourth the lack of level and ability of rural circulation supervision makes it difficult to obtain the corresponding mechanism to solve the information asymmetry, thus making it more difficult to identify the circulation entities in rural areas. In most areas, the administrative departments of rural industry and commerce have fewer personnel, with low professional strength and level and lack of advanced technical inspection tools, so that they cannot identify the fake and inferior commodities timely. Many government supervision departments, such as Food and 
Drug Administration, Ministry of Commerce are only set up in the county. If any problems occurred, rural consumers cannot effectively and timely deal with it. All of these have led to difficulties that effective supervision cannot be place timely if there is any problem in rural commodities.

\section{SignAL TRANSMISSION, INFINITE GAME AND} CONSTRUCTION OF RURAL CIRCULATION SYSTEM IN CHINA

\section{A. Effective Method to Solve Rural Consumers' Adverse Choice - Signal Transmission}

In order to solve the problem of adverse selection in the process of circulation, we put forward the concept of "signal transmission". Signal transmission refers to the action taken by a party with information superiority (the party owning private information) to send relevant signals to another party with information inferior (the party owning public information). And it can avoid adverse selection and improve the operation of market. Under the condition of asymmetric information, information exchange between farmers and circulation enterprises is a dynamic game of incomplete information. The common problem of enterprises operating inferior commodity lies in lack of credit, or the existence of opportunistic behavior, which brings farmers consumption risk. In order to make circulation enterprises operate regular commodities, and reduce the investigation cost of farmers before consumption, circulation enterprises should take the initiative to provide relevant indicators such as their own business conditions, development planning, product sources and product categories. And after farmers observed the information provided by the enterprise, they can judge the authenticity of information provided by the enterprise according to the relevant evaluation system, or objectively evaluate the circulation enterprises by means of a third party credit institutions.

To illustrate the evasion and improvement of adverse selection in the process of circulation enterprises participating in rural circulation process, a signaling game model can be established. Suppose that there are two periods T1, T2, and two participants (the circulating enterprise and the farmer) make $£ 2$ as the second period profit of the SMEs, which is distributed on the interval. Suppose the circulation enterprise know the exact value, but farmers only know the probability distribution. The circulation enterprises choose to transmit credit signal X (including company quality, financial quality, development prospects, economic benefit forecast, solvency prediction and other indicators). From the observed signal X, the farmers infer that the expected profit of the enterprise after selling commodities is $\theta(\mathrm{x})$, and the enterprise's value expected by farmers is $\pi$. In the T era, corporate profits can be realized.

There are three types of equilibrium in signal game transmission: separation equilibrium, pooling equilibrium and semi-separating equilibrium. Separation equilibrium refers that the signals transmitted by a circulation enterprise can reflect the real type of the enterprise and provide sufficient information and basis for farmers' judgment. Separation equilibrium is the equilibrium state expected by farmers, so we only consider separation equilibrium here. According to the above, the following contents can be obtained:

$$
\frac{\partial^{2} \mu(\mathbf{x I V}(\mathbf{x}) \mid \boldsymbol{\theta})}{\partial \mathbf{x} \partial \theta}=\frac{\mathbf{y} \mathbf{L}}{\boldsymbol{\theta}^{\mathbf{2}}}>\mathbf{0}
$$

Thus it can be seen that circulation enterprises with higher expected earnings often spend more energy to establish credit, and have low probability of failure. In conclusion, the more real and comprehensive the signal $\mathrm{X}$ that transmitted by the circulation enterprises to the farmers is, the higher their credit ability is. And the enterprises will have the higher quality and the higher expected income level. Therefore, farmers can judge the profitability level of an enterprise by observing the signals transmitted by the enterprise, and then make investment decisions.

\section{B. Reasonable Method to Solve Moral Hazard of Rural Circulation Enterprises - Infinitely Repeated Games}

Multiple game is a dynamic game, which is repeated many times in a stage. There are three characteristics in multiple game: the former stage does not affect the structure of the latter stage. Game participants can observe the results of past games. The total payment of participants is the discount and weighted average of game payment at all stages. In the repeated game model of rural circulation enterprises and rural consumers, it is assumed that the two sides adopt the following "grim strategy": In the first stage, the two sides choose cooperation (high quality products without opportunistic behavior); in the $\mathrm{N}$ stage, if the outcome of the previous $(n-1)$ stage is good service without opportunistic behavior), then the $\mathrm{N}$ stage continue to adopt a cooperative strategy. But if a circulation enterprise once has the inferior product or the rural consumers have the opportunism behavior, then the other party immediately adopts the competitive strategy, and also uses the uncooperative strategy in the future. Under the grim strategy, it is assumed that the game outcomes of the previous $(n-1)$ stages are all good service without opportunistic behavior. In the $\mathrm{N}$ stage, rural circulation enterprises adopt the strategy of providing inferior products for increasing profits. According to the trigger strategy of rural consumers, rural consumers will always adopt a strategy of non-cooperation. Assuming that the discount factor is 1 , for not losing $\delta<\mathbf{1}$, the total payment of poor service strategy adopted by rural circulation enterprises at the $\mathrm{N}$ stage is as follows:

$$
\pi_{1}=F+(n-1)\left(\alpha r_{g}-c_{g}\right)+\left(\alpha r_{b}-c_{b}\right)+0
$$

If the rural circulation enterprises and rural consumers have adopted the strategy of cooperation, that is, the circulation enterprises have provided quality products, the total payment of rural consumers is:

$$
\begin{aligned}
& \pi_{2}=F+n\left(\alpha r_{g}-c_{g}\right)+\delta_{1}\left(\alpha r_{g}-c_{g}\right)+\delta_{1}^{2}\left(\alpha r_{g}-c_{g}\right)+\cdots \\
& =F+(n-1)\left(\alpha r_{g}-c_{g}\right)+\frac{1}{1-\delta_{1}}\left(\alpha r_{g}-c_{g}\right) \\
& \text { If } \pi_{2}>\pi_{1} \text {, i.e. }
\end{aligned}
$$


$\pi_{2}-\pi_{1}=\frac{1}{1-\delta .}\left(\alpha r_{g}-c_{g}\right)-\left(\alpha r_{b}-c_{b}\right)>0$,

After the arrangement, it is got:

$$
\delta_{1}>\frac{\left(\alpha r_{b}-c_{b}\right)-\left(\alpha r_{g}-c_{g}\right)}{\alpha r_{b}-c_{b}}=\frac{\alpha\left(r_{b}-r_{g}\right)+\left(c_{g}-c_{b}\right)}{\alpha r_{b}-c_{b}}>0
$$

When the above inequality is established, it is explained that if either party of the rural circulation enterprises and the rural consumers adopt the "grim strategy", the best strategy for the other party is to adopt a cooperative strategy all the time. From the above game analysis, we can draw the following conclusions:

(1) The discount factor $\delta$ affects the discount value of future earnings, and its size can measure the patience of participants. So long as the rural circulation enterprises and rural consumers have enough patience $\left(\delta_{1} \geq \delta_{1}^{*}, \quad \delta_{2} \geq \delta_{2}^{*}\right)$, that is, we must pay attention to the benefits arising from long-term cooperation in the rural circulation system, the long-term benefits of adopting the strategy of high-quality products by rural circulation enterprises will be greater than those of adopting the strategy of low-quality products. The long-term benefits of rural consumers' non-occurrence of opportunistic behavior are greater than the benefits of the occurrence. At this time, the rural circulation enterprises and rural consumers will get out of the prisoner's dilemma. Therefore, the rural circulation enterprises should attach importance to the long-term development of rural circulation system. It is needed to improve the quality of rural circulation services and provide the rural consumers with help and services as far as possible, so as to make rural consumers full of hope for the future of rural circulation enterprises (that is, being patient enough). This can effectively curb opportunistic behavior.

(2) If there is a smaller income gap between the benefits that rural circulation enterprises can get from inferior products and that from quality products, that is the value of $\left(\alpha r_{b}-c_{b}\right)-\left(\alpha r_{g}-c_{g}\right)$ is smaller, it indicates that the less the additional income the inferior products bring to the rural circulation enterprises, the less incentive that the rural circulation enterprises have to provide inferior services. From the above form, the smaller the value of

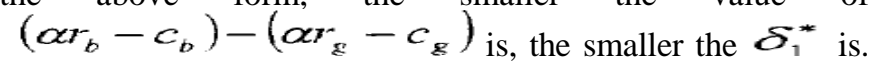
Therefore, the more likely the rural circulation enterprises are to attach importance to long-term development, the more likely the rural circulation enterprises and consumers will reach a strategic balance of cooperation.

\section{Realistic Measures to Solve AdVERSE SELECTION AND MORAL HAZARD IN THE CONSTRUCTION OF RURAL CiRCULATION SYSTEM}

According to the above analysis, the key of solving the adverse selection and moral hazard in the process of rural circulation lies in the credit capacity of enterprises (the transmission capacity of credit signals) and the construction of credit system. It can be solved through the following specific ways.

\section{A. From the Aspect of Circulation Enterprises, We Should} Emphatically Reverse the Circulation Thought of "Attaching Importance to the City and Despising the Countryside ", Improve the Understanding and the Management Level of Circulation Enterprises to the Rural Circulation System, and Enhance the Scale Management Degree of Circulation Enterprise.

1) To reverse the circulation thought of "attaching importance to the city and despising the countryside ": In the course of economic development, many parts of China have been deeply influenced by the ideas of "attaching importance to the city and despising the countryside" and "attaching importance to production and despising circulation". Many policies are oriented on city and production first. In recent years, with the state's emphasis on circulation, more and more circulation policies appear in the local government documents, but the city-first orientation circulation policy is still obvious. The direct consequence of this policy tilt is that the rural circulation market lags behind the cities and lags behind the agricultural production. In the market economy, the market is the basis of resource allocation, guiding the resources to flow from the industries or regions with poor benefit to the industries or regions with good benefit. Because of the vast rural area, relatively decentralized population and poor rural infrastructure, there is a low operating profit. So it is difficult for social capital to flow to the countryside under the market mechanism. With the government's policy of administrative intervention towards cities, the rural production factors flow to the cities in the circulation market, resulting in a growing gap between rural circulation and urban circulation. The backward situation of rural circulation makes it difficult for farmers to raise their income, and save power for the construction of commodity circulation system. Over time, cities continue to improve the efficiency of their own resources, but the efficiency of rural resources is continuously reduced, the distance between urban and rural areas is further widened, this situation will be reciprocating. To break this situation, the government should not only completely reverse the circulation policy of "attaching importance to the city and despising the countryside ", but also tilt the circulation policy toward the countryside.

2) To improve circulation enterprises' understanding and management level of rural circulation system: In China's rural circulation system construction, due to the vague characteristics of rural circulation and insufficient understanding of rural circulation mode, the definition of scope of its responsibilities is still vague. And some enterprises believes that the rural circulation system is simply to meet the general needs of rural consumers, while ignoring the other rights and interests of rural consumers. Under this understanding, circulation enterprises will blindly develop for short-term interests and neglect the service and research of 
rural consumers, lacking of sufficient patience (low value) for the rural circulation system. Even many circulation enterprises (some small business owners rushing to market) regard rural circulation as a "hammer sale". This kind of neglect of long-term development naturally leads to frequent opportunistic behavior between rural circulation enterprises and rural consumers, which affects the further development of rural circulation system. Therefore, in order to improve the rural circulation system, circulation enterprises must adopt standardized business model, use modern information management technology and improve the management level of commodities, so as to win the trust of rural consumers with quality products.

3) To improve the scale operation of circulation enterprises: When farmers participate in market transactions, they are mainly monomers who have no excessive rights in market transaction standards such as prices. In a weak position, they are lack of scale operation of circulation enterprises in the rural areas. In order to create a fair and free competition environment in the rural market of our province, it is urgent for the government to intervene in the rural circulation system construction market, take reasonable measures and encourage large urban distribution enterprises to enter the rural market. And it should stimulate the vitality of rural circulation market, make up for the shortage of market supply in some aspects, and lead scattered farmers to connect with the large market. In addition, our provincial government should focus on improving a number of wholesale markets and farmer's market, to create a competitive and standardized market trading environment. In addition, the production and supply of agricultural materials in rural circulation is still monopolized. The transparency of agricultural commodities market is not high enough, and it is difficult for farmers to grasp the supply and demand information of agricultural materials. It causes that they cannot adjust our production in time according to the market demand. At the same time, farmers' ability to identify commodities is relatively weak. In addition, the idea of seeking cheap goods and the asymmetry of commodity information between buyers and sellers lead to more fake commodities in the rural market of our province, and market disorder is more common.

\section{B. From the Government Level, the Government Should Increase the Input of Information Cost, Strengthen Supervision, Maintain the Order of Rural Circulation Market, Strengthen the Supply of Rural Public Goods, and Improve the Level of Rural Logistics Development}

1. The government should increase the input of information cost, establish the credit database of circulation enterprises, collect, preserve and collate the credit information of enterprises, so as to provide credit report inquiry services for farmers and related information services for circulation supervision and other legal purposes. And the network should be connected to each other, so that in the process of regional circulation, the farmers in other areas can query each other's information through a specific network, so as to evaluate the credit situation of rural circulation enterprises. Farmers can choose companies with good credit and establish long-term and stable relations with them. It is an effective way to eliminate the asymmetric information of the two parties by eliminating the enterprises with poor credit quality from the market.

2. The government should strengthen supervision and control, and severely crack down on illegal practices in the rural market, such as forced quotation and forced trading. At the same time, we should establish a corresponding complaint handling mechanism for rural consumers, so as to ensure the enthusiasm of farmers' consumption. It is also necessary to improve the innovation awareness of rural retail network service, make a detailed analysis of consumption atmosphere, level and group characteristics of the markets at levels of county, township and village in accordance with the actual situation of wide and scattered rural markets. It can create more and better services to serve rural consumers with higher efficiency and level, and stimulate the vitality of rural consumer markets. In addition, we can develop such activities as festival consumption and tourism consumption based on the characteristics of rural areas to enrich the content of rural consumption.

3. To develop e-commerce and improve the development level of rural logistics, and perfect the after-sale service system of rural commodities. We will vigorously develop rural ecommerce and encourage well-known e-commerce enterprises such as Alibaba and Jingdong to cooperate with rural villages and towns and establish Taobao e-commerce villages. In order to encourage logistics enterprises to extend their services to rural areas, the government will subsidize the logistics enterprises that can deliver goods to consumers in rural areas. So that rural residents can enjoy advanced and fast logistics services like urban residents. For a long time, rural consumers have been plagued by simple after-sales services, such as doorto-door installation, maintenance and door-to-door delivery, and the imperfection of after-sales service make many rural consumers lost interest in buying large goods. Therefore, rural commercial enterprises should establish and improve their after-sale service system. By providing door-to-door services such as installation and maintenance to rural customers, they can improve our relationship with rural customers, make consumers in rural areas really save worry in buying and saving, so as to expand their economic benefits. They can also follow the practices of urban convenience service station and establish convenient maintenance points in the county or town's market, so as to solve the problems encountered by customers in buying or using goods, and let consumers have no worries.

\section{From the Consumer Level, Rural Consumers Should Strengthen the Study of Consumption Knowledge, Improve the Level of Consumption Education, and Enhance the Ability to Distinguish Fake Commodities}

Marx pointed out that a person "who want to enjoy in many ways, must have the ability to enjoy, so he must be a highly civilized person." Nowadays, consumer goods are increasing day by day, consumption patterns are emerging one after another, and the use methods become more complicated. 
Consumers in the rural areas should accept consumer education and absorb new ideas and new knowledge, so that they complete their satisfaction when buying goods, and use the goods with high proficiency. We must train rural consumers to form necessary consumption skills. First, the abilities in the process of purchasing preparation, including the ability to identify, evaluate, select and appreciate goods; second, the abilities in the specific consumer behavior, such as the knowledge and use of various consumer goods, such as the rational use, storage and maintenance of high-grade durable consumer goods; it also includes skills training for consumers in various consumer activities. Therefore, it can be seen that training rural consumers to form the necessary consumption skills is an important guarantee to solve the adverse selection of rural consumers.

\section{CONCLUSION}

The construction of rural circulation system is a long-term problem. China's rural circulation system is relatively weak, and there is a big gap between the urban circulation system and the rural. One of the important reasons is that here are the adverse selection and moral hazard in rural circulation construction. To solve these problems, efforts must be made from three levels, circulation enterprises, governments and consumers. That is to say, at the level of circulation enterprises, we should enhance the degree of attention and scale of circulation of enterprises to the rural market. At the government level, we should increase the input of information cost and raise the supervision level. At the consumer level, we should enhance consumer education and enhance the ability of consumers to identify goods. Only in this way can we solve the problem of adverse selection and moral hazard in the construction of rural circulation system.

\section{REFERENCES}

[1] Paddison A, Calderwood E., Rural retailing: a sector in decline? International Journal of Retail \& Distribution Management; 2007, Vol. 35 Issue 2, pp.136-155.

[2] Shaw G, Structure Plan Policies for Retail Provision in Rural Areas: A Case Study of South West England, Service Industries Review, Volume 2, Issue 1, 1982, pp.38-50.

[3] Huang Guoxiong. Suggestions on Promoting Construction of China's Modern Circulation System[J]. Finance \& Trade Economics, 2011(03).

[4] Songze, Wang Xuefeng. Policy Research of Commodity Circulation Increasing Consumption[J]. Finance \& Trade Economics, 2010(11).

[5] Ma Shengtao. Question on Developing Modern Circulation[J].Qiushi, 2007(18).

[6] Ma Longlong. Strengthening Rural Circulation System Construction[N]. Economic Daily, 2009-06-15(6).

[7] Zhang Chuang, Xia Chunyu. Deepening Reform of Rural Circulation System: Systematic Framework and Key Points[J]. Journal of Guangdong Business College, 2008(1).

[8] Lu Song. Henan: Vigorous Development of New Agricultural Business Entities More Than 100,000 Rural Cooperatives [N]. Henan Daily, 2015-07-24.

[9] Xu Congcai, Tang Chengwei. Research on Construction of Circulation System of Modern Agricultural Products[J]. Business Economics and Administration, 2012(4).

[10] Ning Xueping. Adverse Selection and Moral Hazard of Cross Border Financing for Enterprises in the Silk Road Economic Belt [J]. Regional Economic Review, 2016, (4).
[11] Fan Feilong, Research on Credit Signal Transmission Model of SME Financing under Asymmetric Information [J]. Journal of Chongqing University(social science edition), 2002, (6).

[12] Shang Ronghua, Ma Changjie. Promoting Rapid Development of Rural Circulation System by Informatization[J]. Journal of Bohai University, 2014(1).

[13] Wen Xiaowei. Expanding Rural Consumer Demand and Perfecting Rural Distribution System[J]. Academic Research, 2011(8).

[14] Liu Genrong. Construction of Modern Circulation System in Rural Areas during the Transformation Period[J]. China Business and Market, 2012(8).

[15] Li Hong, Shang Yonghua. Research on Innovation of Circulation System of Agricultural Products based on Supply and Marketing Cooperatives: Taking Shanxi as an Example[J]. Journal of Northwest Sci Tech University of Agriculture and Forestry, 2012(2).

[16] Ma Longlong. Discussion on Construction of Market System in the Process of Urban-Rural Integration[J]. Xinhua Digest. 2011(6).

[17] Zhang Ruyi. Cultivation of Circulation Entities of Rural Commerce from the Perspective of Urban-Rural Balance[J]. Business Economics and Administration, 2011(11). 